\title{
Antitumorigenic effect of plumbagin by induction of SH2-containing protein tyrosine phosphatase 1 in human gastric cancer cells
}

\author{
MOON KYUNG JOO ${ }^{1}$, JONG-JAE PARK ${ }^{1}$, SUNG HO KIM ${ }^{1}$, HYO SOON YOO ${ }^{1}$, \\ BEOM JAE LEE ${ }^{1}$, HOON JAI CHUN ${ }^{2}$, SANG WOO LEE ${ }^{3}$ and YOUNG-TAE BAK ${ }^{1}$
}

\begin{abstract}
Division of Gastroenterology, Department of Internal Medicine, Korea University College of Medicine, ${ }^{1}$ Guro Hospital, Seoul 152-703; ${ }^{2}$ Anam Hospital, Seoul 136-705; ${ }^{3}$ Ansan Hospital, Ansan, Gyeonggi 425-707, Republic of Korea
\end{abstract}

Received December 31, 2014; Accepted February 17, 2015

DOI: 10.3892/ijo.2015.2935

\begin{abstract}
A recent study reported that plumbagin downregulated the activity of Janus kinase 2 (JAK2)-signal transducer and activator of transcription 3 (STAT3) pathway to show various antitumor effects in multiple myeloma cells. We aimed in this in vitro study to demonstrate the inhibition of JAK2/STAT3 pathway by plumbagin through inducing SH2-containing protein tyrosine phosphatase 1 (SHP1) expression in the MKN-28 gastric cancer cell line. We performed western blot analysis to measure SHP1, phospho-JAK2/STAT3 level, and observed that plumbagin induced SHP1 expression and simultaneously downregulated phospho-JAK2/STAT3 in MKN-28 cells, with negative SHP1 expression. This effect was consistent when JAK2/STAT3 signaling was activated by interleukin-6 (IL-6), and ameliorated when cells were treated with prevanadate, a protein tyrosin phosphatase inhibitor. Furthermore, plumbagin significantly reduced gene expression of cyclin D1, vascular endothelial growth factor (VEGF)-1, Bcl-xL, survivin and matrix metalloproteinase-9 (MMP-9), known target products of STAT3 activation in gastric cancinogenesis by reverse transcription-polymerase chain reaction (RT-PCR). Several functional studies such as water soluble tetrazolium salt-1 (WST-1) assay, wound closure assay, Matrigel invasion assay and Annexin V assay were also performed, and we validated the functional effect of plumbagin for inhibition of cell proliferation, migration and invasion, and induction of apoptosis. Collectively, our findings suggest that plumbagin is a potential regulator of cellular growth, migration, invasion and apoptosis by inhibiting both
\end{abstract}

Correspondence to: Professor Jong-Jae Park, Division of Gastroenterology, Department of Internal Medicine, Korea University College of Medicine, Guro Hospital, 148 Gurodong-ro, Guro-gu, Seoul 152-703, Republic of Korea

E-mail: gi7pjj@yahoo.co.kr

Key words: plumbagin, Janus kinase 2, signal transducer and activator of transcription 3, SH2-containing protein tyrosine phosphatase 1 constitutive and inducible STAT3 activity through induction of SHP1 in gastric cancer cells.

\section{Introduction}

Gastrointestinal cancers account for a large portion of cancer-related death worldwide, including Korea. Among them, gastric cancer is still one of the most common leading causes of death, and if it is diagnosed in advanced or metastatic stage, the overall prognosis is still poor even though there has been rapid progress for therapeutic modalities of gastric cancer, including surgery or chemotherapy. Thus, there is a need to find novel therapeutic agents effective against malignant gastric disease, especially for advanced or metastatic cancer.

Plumbagin (5-hydroxy-2-methyl-1,4-naphthoquinone) is a quinonoid constituent extracted from the roots of the medicinal plant Plumbago zeylanica L (1). The roots of Plumbago zeylanica have been used for various treatment aims in Oriental medicine fields. One promising effect of plumbagin is that it shows antitumor potential against various types of cancer. For example, an in vivo study demonstrated that plumbagin significantly inhibited the growth of azoxymethane-induced intestinal tumors in rats (2), and several in vitro studies reported that plumbagin showed anti-carcinogenic effects including cell proliferation or invasion or induced cell cycle arrest or apoptosis in breast cancer (3), melanoma (4), non-small lung cancer (5) or prostate cancer cells (6).

Several pivotal studies have clearly demonstrated the molecular mechanisms of antitumor effects of plumbagin in various types of cancer cells. Hafeez et al reported that plumbagin inhibited constitutive expression of epidermal growth factor receptor (EGFR), phosphorylation and DNA binding activity of signal transducer and activator of transcription 3 (STAT3) and nuclear factor- $\kappa \mathrm{B}(\mathrm{NF}-\kappa \mathrm{B})$ in pancreas cancer cells (7). Manu et al showed that plumbagin has a potential blocking activity of CXC chemokine receptor 4 (CXCR4) and potential for inhibition of invasion and migration in breast and gastric cancer cells (8). A recent in vitro study investigated the underlying mechanism of plumbagin in gastric cancer 
cells, and demonstrated that plumbagin inhibited NF- $\mathrm{B}$ p65 nuclear translocation and phosphorylation of $\mathrm{p} 65, \mathrm{I} \kappa \mathrm{B} \alpha$ and $\mathrm{I} \kappa \mathrm{B} \alpha$ kinase $(\mathrm{IKK} \alpha)$, and downregulated NF- $\kappa \mathrm{B}-$ related gene products, such as inhibitor of apoptosis 1 (IAP1), X-linked inhibitor of apoptosis (XIAP), B-cell lymphoma-2 (Bcl-2), Bcl-xL and vascular endothelial growth factor (VEGF) (9). Another well-designed in vitro study showed that plumbagin suppresses STAT3 activation pathway through induction of SH2-containing protein tyrosine phosphatase 1 (SHP1), a non-receptor type protein tyrosine phosphatase (PTPase), in multiple myeloma cells (10). However, impact of plumbagin on STAT3 signaling pathway in gastric carcinogenesis has not been reported yet.

Previously, in vitro, we observed that SHP1 expression was markedly reduced or negative in various gastric cancer cell lines, which was mainly caused by epigenetic silencing mechanism, and exogenous introduction of SHP1 plasmid significantly downregulated Janus kinase 2 (JAK2)/STAT3 pathway and their target genes (unpublished data). From this background, we aimed in this in vitro study to demonstrate the ability of plumbagin to induce SHP1 expression and suppress JAK2/STAT3 signaling pathway in gastric cancer cells.

\section{Materials and methods}

Reagents and cell line. Plumbagin (purity >97\%) was purchased from Sigma-Aldrich (St. Louis, MO, USA) and, dissolved in dimethyl sulfoxide (DMSO) to a concentration of $100 \mathrm{mmol} / \mathrm{l}$ and stored at $-20^{\circ} \mathrm{C}$, and diluted to indicated concentration immediately before use. Recombinant human interleukin-6 (IL-6) and broad-acting PTPase inhibitor sodium pervanadate was purchased from Sigma-Aldrich. A rabbit polyclonal IgG antibody against human SHP1 (sc-287) and $\beta$-actin (sc-47778) was purchased from Santa Cruz Biotechnology, Inc. (Santa Cruz, CA, USA). Mouse monoclonal IgG antibodies against human STAT3 (no. 9139) and phospho-STAT3 (Tyr 705, no. 4113), and rabbit polyclonal antibodies against human JAK2 (no. 3230) and phospho-JAK2 (Tyr 1007/1008, no. 3771) were purchased from Cell Signaling Technology, Inc. (Beverly, MA, USA).

The human gastric cancer cell line (MKN-28) was obtained from Korean Cell Line Bank (Seoul National University, Seoul, Korea), and cultured in RPMI supplemented with $10 \%$ heat-inactivated FBS and penicillin/streptomycin (1.0\%) (all from Gibco, Carlsbad, CA, USA). Cells were incubated in a humidified atmosphere of $5 \% \mathrm{CO}_{2}$ at $37^{\circ} \mathrm{C}$.

Western blot analysis. Total 80-100 $\mu \mathrm{g}$ of cytoplasmic proteins were extracted using CelLytic M (C2978; Sigma-Aldrich) with Complete Mini (pretease inhibitor cocktail; Roche Diagnostics GmbH, Mannheim, Germany). Primary antibodies were diluted at 1:1,000 in the blocking buffer (Tris-buffered saline with Tween-20; Biosesang, Gyeonggi, Korea) containing 5\% non-fat skim milk (Difco; Becton-Dickinson and Co., Sparks, MD, USA). Probed membranes were incubated for $12 \mathrm{~h}$ at $4^{\circ} \mathrm{C}$. The membranes were incubated with goat anti-mouse or anti-rabbit $\mathrm{IgG}$ as a secondary antibody for $1 \mathrm{~h}$ at room temperature. The protein bands were detected by exposing membrane to enhanced chemiluminescence (Perkin-Elmer, Wathman, MA, USA) for $1 \mathrm{~min}$.
Reverse transcription-polymerase chain reaction ( $R T-P C R)$. Total RNA was extracted from whole cells using TRIzol (Invitrogen Life Technologies, Carlsbad, CA, USA) method, and subsequently complementary DNA (cDNA) was produced by using High Capacity cDNA Reverse Transcription kit (Applied Biosystems, Foster City, CA, USA) and treatment with 1 unit of DNase (Promega Corp., Fitchburg, WI, USA). We performed RT-PCR by modifying a previously described method. In brief, $20 \mathrm{ng}$ of prepared cDNA was used to make $25 \mu \mathrm{l}$ of PCR product using EconoTaq ${ }^{\circledR}$ Plus Green Master Mix (Lucigen Corp., Middleton, WI, USA). PCR was done under the following conditions: initial denaturation at $94^{\circ} \mathrm{C}$ ( $2 \mathrm{~min}$ ), followed by $30-40$ cycles of denaturation at $94^{\circ} \mathrm{C}$ (15 sec), annealing at $55^{\circ} \mathrm{C}(15 \mathrm{sec})$, extension at $72^{\circ} \mathrm{C}(15 \mathrm{sec})$ and final extension at $72^{\circ} \mathrm{C}(10 \mathrm{~min})$. The oligonucleotide sequences are summarized in Table I. Glyceraldehyde 3-phosphate dehydrogenase $(G A P D H)$ was used as a housekeeping gene for each sample. PCR products $(5 \mu \mathrm{l})$ were loaded on a $2 \%$ agarose gel, and positive bands were obtained by staining with ethidium bromide (Amresco LLC, Solon, OH, USA).

Water soluble tetrazolium salt-1 (WST-1) cell proliferation assay. To quantify the inhibitory effect of plumbagin on cellular proliferation, we used a commercial WST-1 assay kit (EZ-Cytox; DoGen, Seoul, Korea) as manufacturer's instructions (11). Briefly, $1 \times 10^{4} \mathrm{MKN}-28$ cells/well were cultured in a 96 -well plate at $37^{\circ} \mathrm{C}$ for $24 \mathrm{~h}$, and treated with plumbagin at 20 or $40 \mu \mathrm{M}$ for 3,6 and $9 \mathrm{~h}$. We also cultured untreated cells for the same time period as a control. After treatment, $10 \mu \mathrm{l}$ of WST was added in each well for $4 \mathrm{~h}$, and absorbance at $450 \mathrm{~nm}$ was measured by an ELISA reader (Epoch; BioTek Instruments, Inc., Seoul, Korea). All the experiments were performed in triplicate.

Wound healing assay. After treated with plumbagin at 20 or $40 \mu \mathrm{M}$ for $6 \mathrm{~h}$, cells were equally seeded on a 6 -well plate chamber, and after attachment, a monolayer wound was made using $200 \mu \mathrm{l}$ pipette tip. The media were changed to remove floating debris, and the vertical distance between the sides of the wound was measured at 24 and $48 \mathrm{~h}$ after wound injury using software (12). All the experiments were performed in triplicate.

Matrigel invasion assay. Following treatment with plumbagin at 20 or $40 \mu \mathrm{M}$ for $6 \mathrm{~h}, 4 \times 10^{4}$ cells/well were placed into the 24-well Matrigel Invasion Chambers (BD Biosciences, Franklin Lakes, NJ, USA) in 2\% FBS medium, and in the lower wells $10 \%$ FBS was added. After $24 \mathrm{~h}$ of incubation, filter membranes were stained with crystal violet, and the number of positive invading cells which penetrated through membrane pore was counted under $\times 20$ magnification in at least five randomly selected separate areas.

Annexin $V$ assay. To compare the different percentage of apoptotic cells by plumbagin treatment, we used an Annexin V-FITC assay kit (Anse Technologies Co., Ltd., Seoul, Korea) according to the manufacturer's instructions. Briefly, $1 \times 10^{6} \mathrm{MKN}-28$ cells/well were treated with 20 or $40 \mu \mathrm{M}$ of plumbagin for $6 \mathrm{~h}$, washed and resuspended in binding buffer, followed by staining with an Annexin V-FITC 
Table I. Characteristics of primers for RT-PCR.

\begin{tabular}{|c|c|c|c|c|}
\hline Gene & Primers $\left(5^{\prime} \rightarrow 3^{\prime}\right)$ & $\begin{array}{c}\text { GenBank } \\
\text { accession no. }\end{array}$ & $\begin{array}{l}\text { Size } \\
\text { (bp) }\end{array}$ & Reference \\
\hline SHPI & $\begin{array}{l}\text { F: ACTGGGAGCTGCATCTGAGG } \\
\text { R: CCCACCCTGACGGAGAGC }\end{array}$ & NM_080549.2 & 240 & (31) \\
\hline Cyclin D1 & $\begin{array}{l}\text { F: TTCGGGATGATTGGAATAGC } \\
\text { R: TGTGAGCTGGCTTCATTGAG }\end{array}$ & XM_006718653.1 & 150 & (44) \\
\hline$V E G F-1$ & $\begin{array}{l}\text { F: GGAGTGTGTGCCCACCGAGGAGTCCAAC } \\
\text { R: GGTTCCCGAAACCCTGAGGGAGGCT }\end{array}$ & NM_001287044.1 & 343 & (45) \\
\hline Survivin & $\begin{array}{l}\text { F: TTTCTGCCACATCTGAGTCG } \\
\text { R: TGTCGAGGAAGCTTTCAGGT }\end{array}$ & NM_001012271.1 & 391 & (46) \\
\hline$M M P-9$ & $\begin{array}{l}\text { F: TTGACAGCGACAAGAAGTGG } \\
\text { R: GCCATTCACGTCGTCCTTAT }\end{array}$ & NM_004994.2 & 179 & (47) \\
\hline GAPDH & $\begin{array}{l}\text { F: GGTCTCCTCTGACTTCAACA } \\
\text { R: AGCCAAATTCGTTGTCATAC }\end{array}$ & NM_002046 & 116 & (48) \\
\hline
\end{tabular}

RT-PCR, reverse transcription-polymerase chain reaction; SHP1, SH2-containing protein tyrosine phosphatase 1; VEGF-1, vascular endothelial growth factor-1; MMP-9, matrix metalloproteinase-9; GAPDH, glyceraldehyde 3-phosphate dehydrogenase. F, forward; R, reverse.

and propidium iodide (PI) solution for 10 and $30 \mathrm{~min}$, respectively. After staining, samples were analyzed using FACSCalibur Flow Cytometer (Becton-Dickinson and Co., San Jose, CA, USA).

Statistical analysis. The SPSS ver. 19.0 (SPSS, Inc., Chicago, IL, USA) was used for all analyses. Continuous data are presented as mean \pm standard deviation. A Student's t-test was performed for continuous data, and $\mathrm{p}<0.05$ was considered as statistically significant.

\section{Results}

Plumbagin inhibits phosphorylation of constitutive STAT3 in $M K N-28$ cells. First, we investigated the effect of plumbagin to modulate the activity of JAK2/STAT3 signaling in the gastric cancer cells. MKN-28 cells were treated with different concentration $(10,20$ and $40 \mu \mathrm{M})$ of plumbagin for $6 \mathrm{~h}$, and western blot analysis was performed to measure phosphorylation level of JAK2 at tyrosine 1007/1008 and STAT3 at tyrosine 705. Plumbagin significantly inhibited phosphorylation of JAK2 and STAT3 from $20 \mu \mathrm{M}$, and in contrast, total JAK2 and STAT3 showed similar level regardless of plumbagin treatment, which supports that plumbagin negatively modulates JAK2/STAT3 activity mainly via dephosphorylation rather than protein degradation. Because SHP1 is one of non-transmembrane PTPase which negatively modulate JAK2/STAT3 signaling in epithelial cells (13), we also observed induction of SHP1 expression by plumbagin treatment starting at $20 \mu \mathrm{M}$ (Fig. 1A). Our data suggest that plumbagin might dephosphorylate and downregulate JAK2/STAT3 activity by induction of SHP1 expression in MKN-28 cells. We also observed the time-course to inhibit phosphorylation of JAK2/STAT3 and to induce SHP1 by treatment with $40 \mu \mathrm{M}$ of plumbagin for indicated time points. Phosphorylation of JAK2/STAT3 was ameliorated at $6 \mathrm{~h}$, whereas SHP1 expression appeared at $3 \mathrm{~h}$, which suggests that a time-lag might exist between induction of SHP1 and downregulation of JAK2/STAT3 activity in MKN-28 cells (Fig. 1B).

Plumbagin inhibits IL-6-induced STAT3 phosphorylation in $M K N-28$ cells. Previous in vitro studies demonstrated that stimulation with human recombinant IL-6 upregulates phosphorylated STAT3 level to promote invasive activity in gastric cancer cells $(14,15)$. Thus, we investigated whether plumbagin could modulate IL-6-induced phosphorylation of STAT3 in gastric cancer cells. MKN-28 cells were stimulated with $50 \mathrm{ng} / \mathrm{ml}$ of IL-6 at indicated time points (30 and $60 \mathrm{~min}$ ), and we observed that phosphorylated STAT3 was significantly upregulated from $30 \mathrm{~min}$, whereas SHP1 expression continued to be weakly positive. However, treatment with 20 and $40 \mu \mathrm{M}$ of plumbagin for $6 \mathrm{~h}$, phosphorylated STAT3 ameliorated even in $60 \mathrm{~min}$ stimulation with $50 \mathrm{ng} / \mathrm{ml}$ of IL-6, and SHP1 expression was restored during stimulation (Fig. 2). These findings suggest that plumbagin can also suppress IL-6-induced STAT3 phosphorylation as well as constitutive STAT3 phosphorylation, and SHP1 might play a critical role in this process.

Inhibition of SHP1 restores phosphorylation of JAK2 and STAT3 in MKN-28 cells. Because we observed that SHP1 was implicated in the dephosphorylation and inactivation of JAK2/STAT3 signaling, for the next step, we validated this mechanism by using PTPase inhibitor sodium pervanadate $(10,16,17)$. Treatment with indicated concentration of pervanadate and $40 \mu \mathrm{M}$ of plumbagin for $6 \mathrm{~h}$, and western blot analysis showed that plumbagin downregulated phosphorylation of JAK2 and STAT3, this effect was restored by adding 25 and $50 \mu \mathrm{M}$ of pervanadate, whereas SHP1 expression showed the opposite pattern, it was restored by treatment with plumbagin but ameliorated by combination with pervanadate (Fig. 3). Taken together, these findings 
A

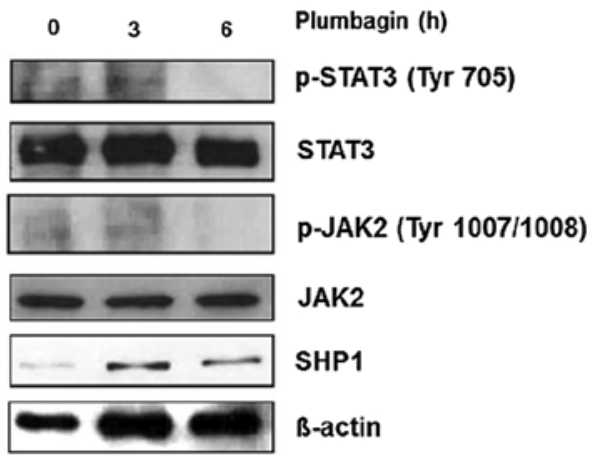

B

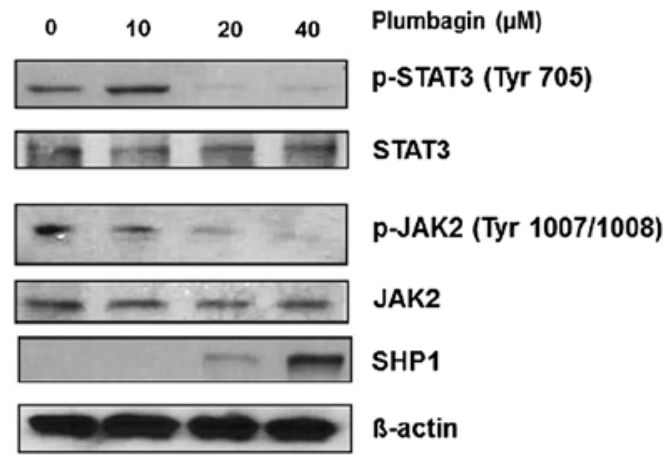

Figure 1. Effect of plumbagin on constitutive Janus kinase 2 (JAK2)/signal transducer and activator of transcription 3 (STAT3) activity and SH2-containing protein tyrosine phosphatase 1 (SHP1) expression. (A) Reduction of p-JAK2/p-STAT3 and restoration of SHP1 expression by various concentrations of plumbagin. MKN-28 cells $\left(2 \times 10^{6}\right)$ were treated with 10,20 and $40 \mu \mathrm{M}$ of plumbagin for $6 \mathrm{~h}$, and then whole cell extracts were collected and probed for p-JAK2, p-STAT3 and SHP1 antibody. (B) Modulation of p-JAK2/p-STAT3 and SHP1 expression by plumbagin at various time points. MKN-28 cells (2x10 ${ }^{6}$ ) were treated with $40 \mu \mathrm{M}$ of plumbagin for 3 and $6 \mathrm{~h}$, and then proteins were prepared and probed for p-JAK2, p-STAT3 and SHP1 antibody.

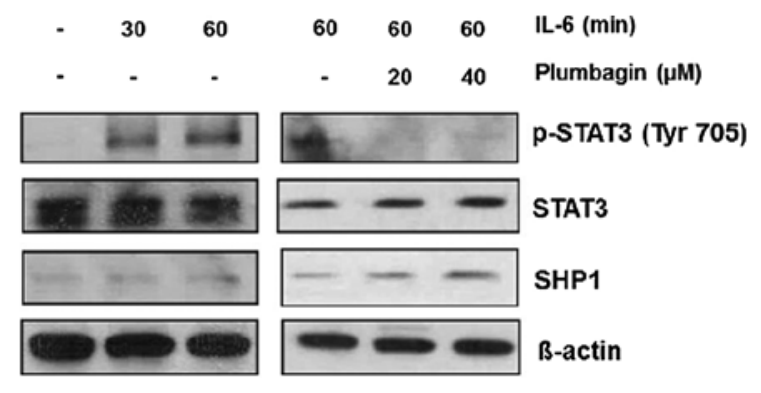

Figure 2. Effects of plumbagin on interleukin-6 (IL-6) inducible signal transducer and activator of transcription 3 (STAT3) activity and SH2-containing protein tyrosine phosphatase 1 (SHP1) expression. (Left panel) MKN-28 cells $\left(2 \times 10^{6}\right)$ were stimulated with $50 \mathrm{ng} / \mathrm{ml}$ of IL- 6 for 30 and $60 \mathrm{~min}$, and then p-STAT3 and SHP1 expression levels were analyzed by western blot analysis. (Right panel) MKN-28 cells $\left(2 \times 10^{6}\right)$ were pre-treated with 20 and $40 \mu \mathrm{M}$ of plumbagin for $6 \mathrm{~h}$, and stimulated with $50 \mathrm{ng} / \mathrm{ml}$ of IL-6 for $60 \mathrm{~min}$. Whole cell extracts were collected and analyzed for p-STAT3 and SHP1 expression.

also support our suggestion that SHP1 might be closely related to the mechanism of plumbagin-induced inhibition of JAK2/STAT3 activity in MKN-28 cells.

Plumbagin downregulates STAT3-associated target genes in $M K N-28$ cells. In various human malignancies including gastric cancer, STAT3 is commonly activated and acts as a pivotal transcription factor to upregulate multiple target genes involving proliferation, invasion/metastasis and anti-apoptosis, such as VEGF-1, matrix metalloproteinase-9 (MMP-9), Bcl-xL, survivin or cyclin D1 (18). To investigate the effect of plumbagin in regulating target gene expression related to STAT3 pathway in gastric cancer cells, treatment with 20 or $40 \mu \mathrm{M}$ of plumbagin was performed for $6 \mathrm{~h}$ with or without stimulation of IL-6, and by RT-PCR. Plumbagin restored SHP1 expression in both constitutive and IL-6-stimulated conditions, and reduced gene expression of VEGF-1, MMP-9, Bcl-xL, survivin and cyclin D1, which were maximally reduced by $40 \mu \mathrm{M}$ concentration (Fig. 4). These findings suggest that plumbagin modulates mRNA expression of STAT3-related target genes via restoration of SHP1 expression in MKN-28 cells.

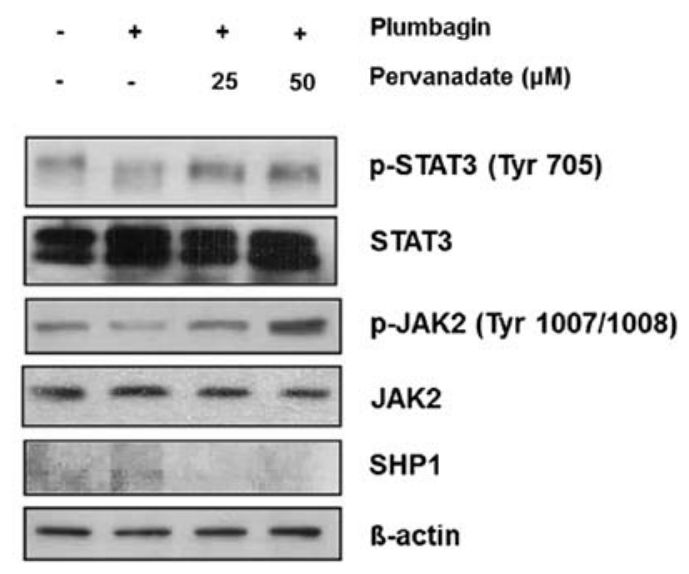

Figure 3. Reversion of p-JAK2/p-STAT3 and amelioration of SH2-containing protein tyrosine phosphatase 1 (SHP1) by pervanadate. MKN-28 cells $\left(2 \times 10^{6}\right)$ were pre-treated with 25 and $50 \mu \mathrm{M}$ of protein tyrosine phosphatase (PTPase) inhibitor sodium pervanadate for $30 \mathrm{~min}$, followed by $40 \mu \mathrm{M}$ of plumbagin for $6 \mathrm{~h}$. Whole cell extracts were used for analysis of p-JAK2, p-STAT3 and SHP1 expression by western blot analysis.

Plumbagin inhibits cell proliferation, migration and invasion, and induces apoptosis in MKN-28 cells. To determine functional effects of plumbagin for STAT3-related cellular proliferation, migration, invasion and apoptosis in gastric cancer cells, MKN-28 cells were treated with 20 or $40 \mu \mathrm{M}$ of plumbagin. By performing WST-1 cell proliferation assay, we observed that plumbagin significantly inhibited cell proliferation in a time- and dose-dependent manner, with maximal inhibitory effect at $40 \mu \mathrm{M}$ in $6 \mathrm{~h}$ treatment (Fig. 5). After treatment with plumbagin for $6 \mathrm{~h}$, we made wound injury in a 6-well plate using a pipette tip, and we observed that plumbagin significantly inhibited wound closure at 24 and $48 \mathrm{~h}$ after injury and this inhibitory effect was more prominent at 40 than $20 \mu \mathrm{M}$ of plumbagin (Fig. 6). We treated MKN-28 cells with 20 or $40 \mu \mathrm{M}$ of plumbagin for $6 \mathrm{~h}$, and cultured for $24 \mathrm{~h}$ in Transwell plate with a pore membrane, and then fixed and stained the cells by crystal violet. We also observed that plumbagin significantly reduced the relative number of 


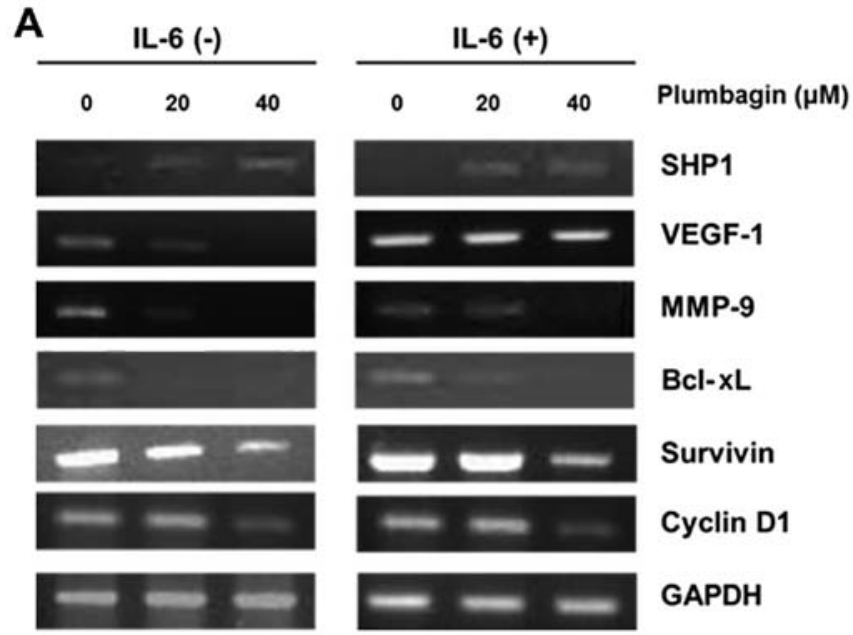

B
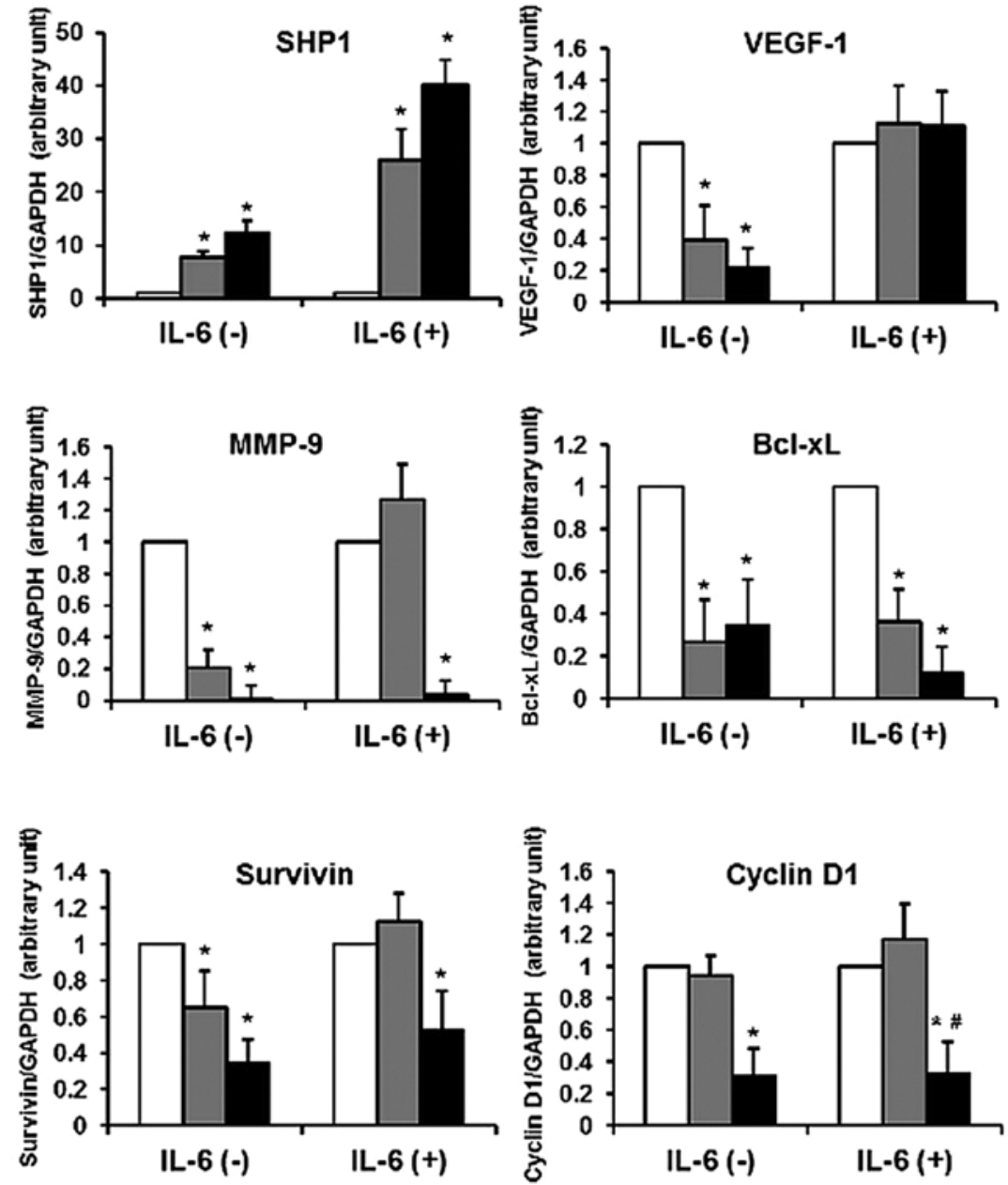

口Control aPlumbagin $20 \mu / M \quad$ aPlumbagin $40 \mu / 4$

Figure 4. Effects of plumbagin in modulation of signal transducer and activator of transcription 3 (STAT3)-related target gene expression. (A) MKN-28 cells were treated with 20 or $40 \mu \mathrm{M}$ of plumbagin for $6 \mathrm{~h}$ with or without stimulation with $50 \mathrm{ng} / \mathrm{ml}$ of interleukin-6 (IL-6) for $60 \mathrm{~min}$. Total RNA was extracted from each sample and used for reverse transcription-polymerase chain reaction (RT-PCR) analysis. (B) Densitometric analysis of vascular endothelial growth factor (VEGF)-1, matrix metalloproteinase-9 (MMP-9), survivin and cyclin D1. Data are expressed as mean \pm standard deviation, and obtained from triplicate. ${ }^{*} \mathrm{P}<0.05$, compared with control, ${ }^{\#} \mathrm{p}<0.05$, compared with plumbagin $20 \mu \mathrm{M}$.

invading cells, and $40 \mu \mathrm{M}$ of plumbagin was more effective than $20 \mu \mathrm{M}$ (Fig. 7). Finally, we investigated pro-apoptotic effect of plumbagin by Annexin V assay, and relative number of apoptotic cells was significantly increased by $40 \mu \mathrm{M}$ of plumbagin, rather than $20 \mu \mathrm{M}$ (Fig. 8). Taken together, these findings suggest that plumbagin significantly inhibits cell 


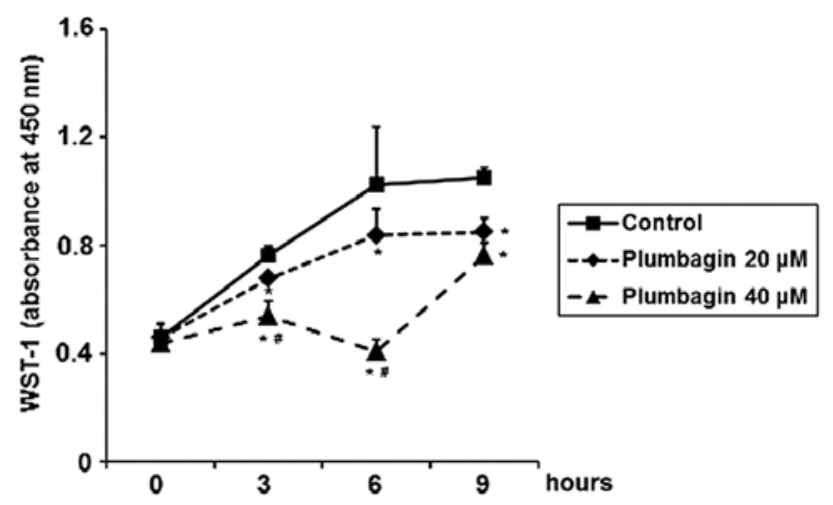

Figure 5. Effects of plumbagin for cellular proliferation. MKN-28 cells ( $1 \times 10^{4}$ cells/well) were treated with plumbagin at 20 or $40 \mu \mathrm{M}$ for 3,6 and 9 h. Data are the absorbance at $450 \mathrm{~nm}$ by an ELISA reader and expressed as mean \pm standard deviation. All experiments were performed in triplicate. " $\mathrm{P}<0.05$, compared with control, ${ }^{\#} \mathrm{p}<0.05$, compared with plumbagin $20 \mu \mathrm{M}$.

A
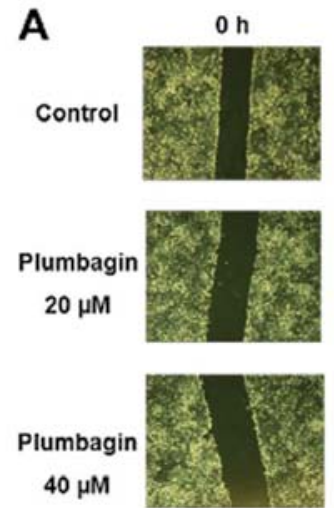

$24 \mathrm{~h}$
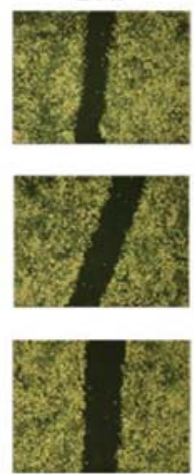

$48 \mathrm{~h}$
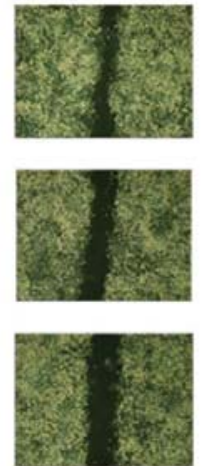

B

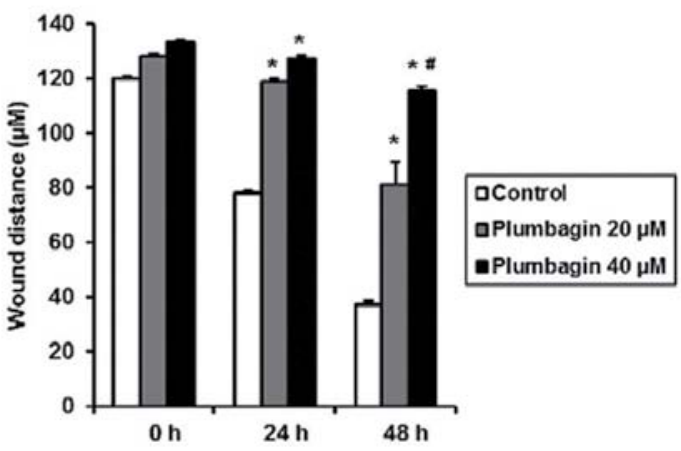

Figure 6. Effects of plumbagin for cell migration. (A) Representative images of wound closure. MKN-28 cells were treated with plumbagin at 20 or $40 \mu \mathrm{M}$ for $6 \mathrm{~h}$, and then cells were equally seeded on a 6-well plate chamber and a monolayer wound was made using $200 \mu 1$ pipette tip. (B) Analysis of vertical wound distance. The vertical distance between the sides of the wound was measured at 24 and $48 \mathrm{~h}$ after wound injury. Data are presented as mean \pm standard deviation. All experiments were performed in triplicate. ${ }^{*} \mathrm{P}<0.05$, compared with control, ${ }^{*} \mathrm{p}<0.05$, compared with plumbagin $20 \mu \mathrm{M}$.
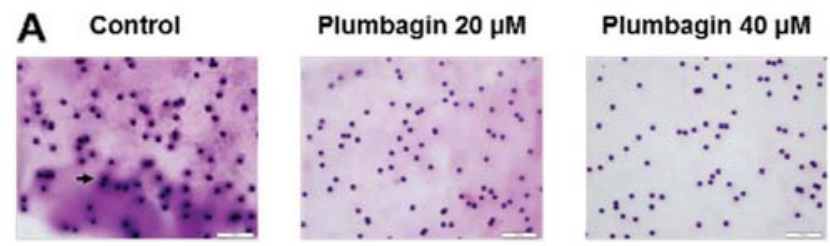

B

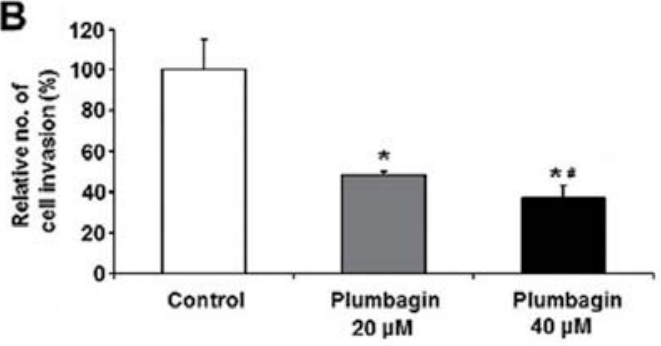

Figure 7. Effects of plumbagin for cell invasion. (A) Representative images of Matrigel invasion assay. MKN-28 cells $\left(4 \times 10^{4}\right.$ cells/well) were treated with plumbagin at 20 or $40 \mu \mathrm{M}$ for $6 \mathrm{~h}$, and placed into the 24-well Matrigel invasion chambers. After $24 \mathrm{~h}$, filter membranes were stained with crystal violet. White bar indicates $50 \mu \mathrm{m}$. (B) Analysis of invading cells. The number of positive invading cells was counted under $\mathrm{x} 20$ magnification. Relative number of positive cells was calculated by regarding the number of positive cells in control group as $100 \%$. Data are presented as mean \pm standard deviation. Cell counting was performed in at least five randomly selected separate areas. ${ }^{*} \mathrm{P}<0.05$, compared with control, ${ }^{*} \mathrm{p}<0.05$, compared with plumbagin $20 \mu \mathrm{M}$. proliferation, migration and invasion, and induces cellular apoptosis in MKN-28 cells, and these functional effects are dose-dependent.

\section{Discussion}

In this in vitro study, we showed that plumbagin restored SHP1 expression to downregulated JAK2/STAT3 activity and their target genes, and consequentially, led to anti-proliferative, migratory, invasive and pro-apoptotic effects in gastric carcinoma cells. To our knowledge, our study firstly demonstrates that plumbagin inhibits STAT3 pathway through induction of SHP1 activity in stomach cancer cells. Little has been reported about anti-cancer role of plumbagin in gastric cancer, and only few studies focused on its inhibitory effects on NF- $\kappa B$ or CXCR4 pathway $(8,9)$, or cytoxic effect through generation of reactive oxygen species (ROS) (19). Also, recent studies reported several candidate molecules to downregulate JAK2/STAT3 activity and exhibit antitumor effect in gastric cancer cells (20-23). However, none of them showed molecular link between SHP1 and JAK2/STAT3 pathway in gastric cancer cells.

SHP1 is non-receptor-type PTPase, which is encoded by PTPN6 gene located on human chromosome 12p13 (24), and 
A

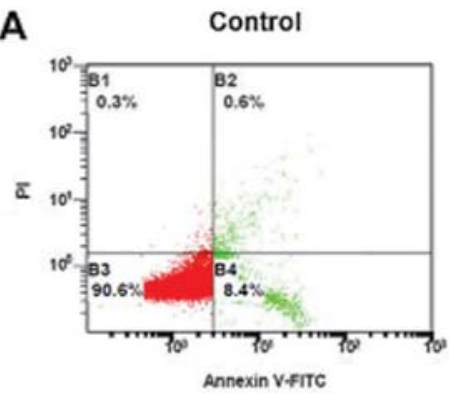

A

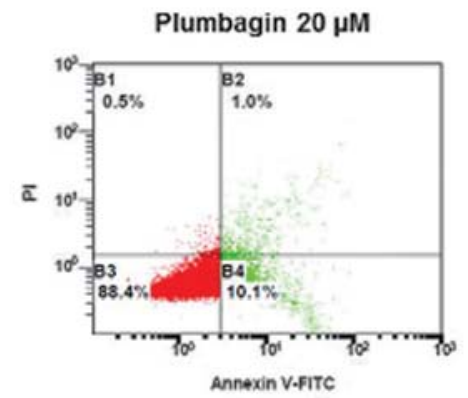

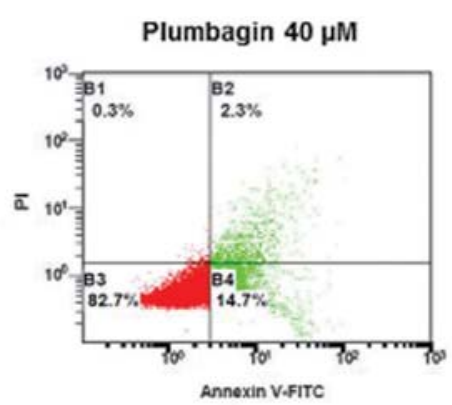

B

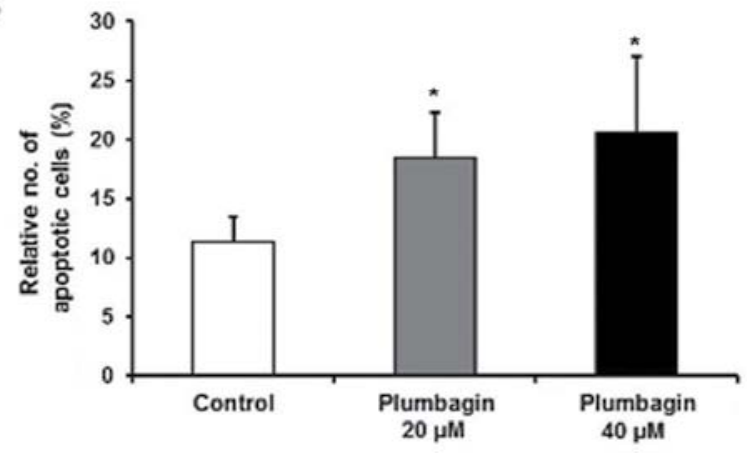

Figure 8. Enhancing effect of apoptosis by plumbagin treatment. (A) Representative images of Annexin V-FITC assay. MKN-28 cells (1x10 6 cells/well) were treated with plumbagin at 20 or $40 \mu \mathrm{M}$ for $6 \mathrm{~h}$, and stained with Annexin V-FITC and propidium iodide (PI) solution. (B) Analysis of apoptotic cells. Data are presented as mean \pm standard deviation. All experiments were performed in triplicate. ${ }^{*} \mathrm{P}<0.05$, compared with control.

it has been reported as a negative regulator of JAK2/STAT3 activity by dephosphorylation of JAK 2 and STAT3 to act as a PTPase $(25,26)$. Previous studies demonstrated that SHP1 is inactivated by aberrant methylation of $\mathrm{CpG}$ island promoter in various hematopoietic malignancies, and their functional roles have been extensively investigated in hematopoietic cancer cells (27-30). However, only few studies reported CpG island promoter hypermethylation in epithelial cells such as colon cancer cells $(13,31)$, and little is known about reduced gene expression or promoter hypermethylation of SHP1 in gastric cancer cells except that several studies briefly reported the methylation rate of $\mathrm{CpG}$ island promoter of SHP1 in gastric carcinoma tissues $(32,33)$. In colon cancer cells, SHP1 expression was mainly regulated by DNA methylation and upregulated by DNA methyltransferase inhibitors such as 5-aza-2'-deoxycytidine (5-aza-dC). Furthermore, increased SHP1 expression by transfection with SHP1 plasmid vector or treatment with demethylating agent such as 5-aza-dC substantially decreased p-JAK2/p-STAT3 level (13). We observed previously that SHP1 expression was epigenetically regulated and closely related with STAT3 activity in gastric cancer cells (unpublished data). Thus, as the next step, we searched for a candidate molecule which can induce SHP1 expression in gastric cancer cells, and demonstrated that plumbagin might be a potential inducer of SHP1 to inhibit JAK2/STAT3 pathway.

Previous pivotal studies extensively investigated the crucial role of STAT3 for initiation and progression of gastric cancer. Persistent infection of CagA-positive Helicobacter pylori (H. pylori) strain activates constitutive STAT3 via chronic JAK2 activity, which in turn promotes target gene transcription associated with proliferation, invasion, metastasis and angiogenesis. In terms of gastric epithelial cells,
IL-6 family ligands such as IL-6 and IL-11 is associated with chronic inflammation by CagA-positive $H$. pylori and development of gastric cancer $(18,34)$. The suppressors of cytokine signaling (SOCS) family proteins such as SOCS -1 or -3 have been reported as important regulators of JAK2/STAT3 pathway by negative feedback mechanism $(35,36)$. Numerous PTPases have been presented as promising targets to inhibit STAT3 signaling in various kinds of cancer, including SHP1 (37), SHP2 (38), PTP-1D (39) and PTEN (40). However, little is known about the expression level and roles of PTPase in gastric tumorigenesis, and their inhibitory action on STAT3 signaling is still controversial. Several previous studies have focused on the effect of SHP2, and an in vitro study demonstrated that phosphorylated CagA preferentially activates SHP2/extracellular signal-regulated kinase (ERK) pathway and induces cell growth inhibition (41), whereas immunohistochemical studies using human stomach tissues showed that SHP2 expression was significantly enhanced in $H$. pylori-infected gastric cancer $(42,43)$. Previously, we observed that exogenous expression of SHP1 in gastric cancer cells significantly inhibited cellular proliferation, migration and invasion (unpublished data), however, this phenomenon should be further validated in immunohistochemical studies using human gastric carcinoma tissues. This study might further support the hypothesis that SHP1 negatively regulates STAT3 activity because induction of SHP1 by plumbagin inhibited JAK2/STAT3 signaling and inhibition of SHP1 reversed the plumbagin effects on JAK2/STAT3 pathway.

In conclusion, our study suggests that plumbagin might have promising anti-cancer potential via upregulation of SHP1 expression and inhibition of JAK2/STAT3 pathway in gastric cancer cells, and SHP1 might be an alternative target 
to regulate STAT3 activity in gastric carcinogenesis. Further preclinical studies concerning the effects of plumbagin in STAT3 overexpressing gastric cancer should be performed, and also other promising agents which can upregulate SHP1 expression in gastric cancer cells need to be investigated.

\section{Acknowledgements}

This research was financially supported by grants from Korea University (Seoul, Korea) (grant no. R1211041) and Pacific Pharma Corp. (Seoul, Korea) (grant no. Q1307141).

\section{References}

1. Sandur SK, Ichikawa H, Sethi G, Ahn KS and Aggarwal BB Plumbagin (5-hydroxy-2-methyl-1,4-naphthoquinone) suppresses NF-kappaB activation and NF-kappaB-regulated gene products through modulation of p65 and IkappaBalpha kinase activation, leading to potentiation of apoptosis induced by cytokine and chemotherapeutic agents. J Biol Chem 281: 17023-17033, 2006.

2. Sugie S, Okamoto K, Rahman KM, Tanaka T, Kawai K Yamahara $J$ and Mori H: Inhibitory effects of plumbagin and juglone on azoxymethane-induced intestinal carcinogenesis in rats. Cancer Lett 127: 177-183, 1998.

3. Kuo PL, Hsu YL and Cho CY: Plumbagin induces G2-M arrest and autophagy by inhibiting the AKT/mammalian target of rapamycin pathway in breast cancer cells. Mol Cancer Ther 5: 3209-3221, 2006.

4. Hsu YL, Cho CY, Kuo PL, Huang YT and Lin CC: Plumbagin (5-hydroxy-2-methyl-1,4-naphthoquinone) induces apoptosis and cell cycle arrest in A549 cells through p53 accumulation via c-Jun NH2-terminal kinase-mediated phosphorylation at serine 15 in vitro and in vivo. J Pharmacol Exp Ther 318 : 484-494, 2006.

5. Wang CC, Chiang YM, Sung SC, Hsu YL, Chang JK and Kuo PL: Plumbagin induces cell cycle arrest and apoptosis through reactive oxygen species/c-Jun N-terminal kinase pathways in human melanoma A375.S2 cells. Cancer Lett 259: 82-98, 2008.

6. Powolny AA and Singh SV: Plumbagin-induced apoptosis in human prostate cancer cells is associated with modulation of cellular redox status and generation of reactive oxygen species. Pharm Res 25: 2171-2180, 2008.

7. Hafeez BB, Jamal MS, Fischer JW, Mustafa A and Verma AK Plumbagin, a plant derived natural agent inhibits the growth of pancreatic cancer cells in in vitro and in vivo via targeting EGFR, Stat 3 and NF- $\mathrm{KB}$ signaling pathways. Int J Cancer 131: 2175-2186, 2012.

8. Manu KA, Shanmugam MK, Rajendran P,Li F, Ramachandran L, Hay HS, Kannaiyan R, Swamy SN, Vali S, Kapoor S, et al: Plumbagin inhibits invasion and migration of breast and gastric cancer cells by downregulating the expression of chemokine receptor CXCR4. Mol Cancer 10: 107, 2011.

9. Li J, Shen L, Lu FR, Qin Y, Chen R, Li J, Li Y, Zhan HZ and He YQ: Plumbagin inhibits cell growth and potentiates apoptosis in human gastric cancer cells in vitro through the NF- $\kappa B$ signaling pathway. Acta Pharmacol Sin 33: 242-249, 2012.

10. Sandur SK, Pandey MK, Sung B and Aggarwal BB: 5-hydroxy2-methyl-1,4-naphthoquinone, a vitamin K3 analogue, suppresses STAT3 activation pathway through induction of protein tyrosine phosphatase, SHP-1: Potential role in chemosensitization. Mol Cancer Res 8: 107-118, 2010.

11. Huang Z,Lee H, Lee E, Kang SK, Nam JM and Lee M: Responsive nematic gels from the self-assembly of aqueous nanofibres. Nat Commun 2: 459, 2011.

12. Dallol A, Agathanggelou A, Tommasi S, Pfeifer GP, Maher ER and Latif F: Involvement of the RASSF1A tumor suppressor gene in controlling cell migration. Cancer Res 65: 7653-7659, 2005.

13. Xiong H, Chen ZF, Liang QC, Du W, Chen HM, Su WY, Chen GQ, Han ZG and Fang JY: Inhibition of DNA methyltransferase induces G2 cell cycle arrest and apoptosis in human colorectal cancer cells via inhibition of JAK2/STAT3/STAT5 signalling. J Cell Mol Med 13: 3668-3679, 2009.

14. Lin MT, Lin BR, Chang CC, Chu CY, Su HJ, Chen ST, Jeng YM and Kuo ML: IL-6 induces AGS gastric cancer cell invasion via activation of the c-Src/RhoA/ROCK signaling pathway. Int J Cancer 120: 2600-2608, 2007.
15. Zhu BH, Chen HY, Zhan WH, Wang CY, Cai SR, Wang Z, Zhang $\mathrm{CH}$ and He YL: (-)-Epigallocatechin-3-gallate inhibits VEGF expression induced by IL-6 via Stat 3 in gastric cancer. World J Gastroenterol 17: 2315-2325, 2011.

16. Rhee YH, Jeong SJ, Lee HJ, Lee HJ, Koh W, Jung JH, Kim SH and Sung-Hoon K: Inhibition of STAT3 signaling and induction of SHP1 mediate antiangiogenic and antitumor activities of ergosterol peroxide in U266 multiple myeloma cells. BMC Cancer 12: 28 , 2012.

17. Lee JH, Chiang SY, Nam D, Chung WS, Lee J, Na YS, Sethi G and Ahn KS: Capillarisin inhibits constitutive and inducible STAT3 activation through induction of SHP-1 and SHP-2 tyrosine phosphatases. Cancer Lett 345: 140-148, 2014.

18. Jackson CB and Giraud AS: STAT3 as a prognostic marker in human gastric cancer. J Gastroenterol Hepatol 24: 505-507, 2009.

19. Kim JA, Lee EK, Park SJ, Kim ND, Hyun DH, Lee CG, Lee JH, Yang KM, Heo K and Son TG: Novel anti-cancer role of naphthazarin in human gastric cancer cells. Int J Oncol 40: 157-162, 2012.

20. Chen J, Wang J, Lin L, He L, Wu Y, Zhang L, Yi Z, Chen Y, Pang $X$ and Liu M: Inhibition of STAT3 signaling pathway by nitidine chloride suppressed the angiogenesis and growth of human gastric cancer. Mol Cancer Ther 11: 277-287, 2012.

21. Jia Y, Liu D, Xiao D, Ma X, Han S, Zheng Y, Sun S, Zhang M, Gao H, Cui X, et al: Expression of AFP and STAT3 is involved in arsenic trioxide-induced apoptosis and inhibition of proliferation in AFP-producing gastric cancer cells. PLoS One 8: e54774, 2013.

22. Kim MJ, Nam HJ, Kim HP, Han SW, Im SA, Kim TY, Oh DY and Bang YJ: OPB-31121, a novel small molecular inhibitor, disrupts the JAK2/STAT3 pathway and exhibits an antitumor activity in gastric cancer cells. Cancer Lett 335: 145-152, 2013.

23. Katsha A, Arras J, Soutto M, Belkhiri A and El-Rifai W: AURKA regulates JAK2-STAT3 activity in human gastric and esophageal cancers. Mol Oncol 8: 1419-1428, 2014.

24. López-Ruiz P, Rodriguez-Ubreva J, Cariaga AE, Cortes MA and Colás B: SHP-1 in cell-cycle regulation. Anticancer Agents Med Chem 11: 89-98, 2011.

25. Zhang J, Somani AK and Siminovitch KA: Roles of the SHP-1 tyrosine phosphatase in the negative regulation of cell signalling. Semin Immunol 12: 361-378, 2000.

26. Wu C, Sun M, Liu L and Zhou GW: The function of the protein tyrosine phosphatase SHP-1 in cancer. Gene 306: 1-12, 2003.

27. Han Y, Amin HM, Franko B, Frantz C, Shi X and Lai R: Loss of SHP1 enhances JAK3/STAT3 signaling and decreases proteosome degradation of JAK3 and NPM-ALK in ALK+ anaplastic large-cell lymphoma. Blood 108: 2796-2803, 2006.

28. Oka T, Ouchida M, Koyama M, Ogama Y, Takada S, Nakatani Y, Tanaka T, Yoshino T, Hayashi K, Ohara N, et al: Gene silencing of the tyrosine phosphatase SHP1 gene by aberrant methylation in leukemias/lymphomas. Cancer Res 62: 6390-6394, 2002.

29. Koyama M, Oka T, Ouchida M,Nakatani Y,Nishiuchi R, Yoshino T, Hayashi K, Akagi T and Seino Y: Activated proliferation of B-cell lymphomas/leukemias with the SHP1 gene silencing by aberrant CpG methylation. Lab Invest 83: 1849-1858, 2003.

30. Chim CS, Fung TK, Cheung WC, Liang R and Kwong YL: SOCS1 and SHP1 hypermethylation in multiple myeloma: Implications for epigenetic activation of the Jak/STAT pathway. Blood 103: 4630-4635, 2004.

31. Ruchusatsawat K, Wongpiyabovorn J, Shuangshoti S, Hirankarn N and Mutirangura A: SHP-1 promoter 2 methylation in normal epithelial tissues and demethylation in psoriasis. J Mol Med (Berl) 84: 175-182, 2006.

32. Bernal C, Aguayo F, Villarroel C, Vargas M, Díaz I, Ossandon FJ, Santibáñez E, Palma M, Aravena E, Barrientos C, et al: Reprimo as a potential biomarker for early detection in gastric cancer. Clin Cancer Res 14: 6264-6269, 2008.

33. Ksiaa F, Ziadi S, Amara K, Korbi S and Trimeche M: Biological significance of promoter hypermethylation of tumor-related genes in patients with gastric carcinoma. Clin Chim Acta 404: 128-133, 2009.

34. Giraud AS, Menheniott TR and Judd LM: Targeting STAT3 in gastric cancer. Expert Opin Ther Targets 16: 889-901, 2012.

35. Souma Y, Nishida T, Serada S, Iwahori K, Takahashi T, Fujimoto M, Ripley B, Nakajima K, Miyazaki Y, Mori M, et al: Antiproliferative effect of SOCS-1 through the suppression of STAT3 and p38 MAPK activation in gastric cancer cells. Int J Cancer 131: 1287-1296, 2012.

36. Inagaki-Ohara K, Mayuzumi H, Kato S, Minokoshi Y, Otsubo T, Kawamura YI, Dohi T, Matsuzaki G and Yoshimura A: Enhancement of leptin receptor signaling by SOCS3 deficiency induces development of gastric tumors in mice. Oncogene 33: 74-84, 2014. 
37. Tenev T, Böhmer SA, Kaufmann R, Frese S, Bittorf T, Beckers T and Böhmer FD: Perinuclear localization of the protein-tyrosine phosphatase SHP-1 and inhibition of epidermal growth factorstimulated STAT1/3 activation in A431 cells. Eur J Cell Biol 79: 261-271, 2000.

38. Kim H and Baumann $\mathrm{H}$ : Dual signaling role of the protein tyrosine phosphatase SHP-2 in regulating expression of acute-phase plasma proteins by interleukin- 6 cytokine receptors in hepatic cells. Mol Cell Biol 19: 5326-5338, 1999.

39. Gunaje JJ and Bhat GJ: Involvement of tyrosine phosphatase PTP1D in the inhibition of interleukin-6-induced Stat3 signaling by alpha-thrombin. Biochem Biophys Res Commun 288: 252-257, 2001

40. Irie-Sasaki J, Sasaki T, Matsumoto W, Opavsky A, Cheng M, Welstead G, Griffiths E, Krawczyk C, Richardson CD, Aitken K, et al: CD45 is a JAK phosphatase and negatively regulates cytokine receptor signalling. Nature 409: 349-354, 2001.

41. Lee IO, Kim JH, Choi YJ, Pillinger MH, Kim SY, Blaser MJ and Lee YC: Helicobacter pylori CagA phosphorylation status determines the gp130-activated SHP2/ERK and JAK/STAT signal transduction pathways in gastric epithelial cells. J Biol Chem 285: 16042-16050, 2010.

42. Jiang J, Jin MS, Kong F, Wang YP, Jia ZF, Cao DH, Ma HX, Suo J and Cao XY: Increased expression of tyrosine phosphatase SHP-2 in Helicobacter pylori-infected gastric cancer. World J Gastroenterol 19: 575-580, 2013.
43. Kim JS, Shin OR, Kim HK, Cho YS, An CH, Lim KW and Kim SS: Overexpression of protein phosphatase non-receptor type 11 (PTPN11) in gastric carcinomas. Dig Dis Sci 55: 1565-1569, 2010.

44. Jiménez DJ, Montaña JS, Alvarez D and Baena S: A novel cold active esterase derived from Colombian high Andean forest soil metagenome. World J Microbiol Biotechnol 28: 361-370, 2012.

45. Gu X, Cun Y, Li M, Qing Y, Jin F, Zhong Z, Dai N, Qian C, Sui J and Wang D: Human apurinic/apyrimidinic endonuclease siRNA inhibits the angiogenesis induced by X-ray irradiation in lung cancer cells. Int J Med Sci 10: 870-882, 2013.

46. McTavish N, Copeland LA, Saville MK, Perkins ND and Spruce BA:Proenkephalin assists stress-activated apoptosis through transcriptional repression of NF-kappaB- and p53-regulated gene targets. Cell Death Differ 14: 1700-1710, 2007.

47. Takei Y, Kadomatsu K, Yuzawa Y, Matsuo S and Muramatsu T: A small interfering RNA targeting vascular endothelial growth factor as cancer therapeutics. Cancer Res 64: 3365-3370, 2004.

48. Rivera MN, Kim WJ, Wells J, Stone A, Burger A, Coffman EJ, Zhang $\mathrm{J}$ and Haber DA: The tumor suppressor WTX shuttles to the nucleus and modulates WT1 activity. Proc Natl Acad Sci USA 106: 8338-8343, 2009 